\title{
Estimation of $\mathrm{CO}_{2}$ Storage Capacity in the Real Sub-Seabed Sediments by Gas Hydrate*
}

\author{
Tao Yu ${ }^{1,2 \#, ~ T o r u ~ S a t o ~}{ }^{1}$, Abuliti Abudula ${ }^{2}$ \\ ${ }^{1}$ Department of Ocean Technology, Policy, and Environment, University of Tokyo, Kashiwa, Japan \\ ${ }^{2}$ Graduate School of Science and Technology, Hirosaki University, Hirosaki, Japan \\ Email: "yutao@hirosaki-u.ac.jp
}

How to cite this paper: $\mathrm{Yu}, \mathrm{T}$., Sato, T. and Abudula, A. (2018) Estimation of $\mathrm{CO}_{2}$ Storage Capacity in the Real Sub-Seabed Sediments by Gas Hydrate. Journal of Flow Control, Measurement \& Visualization, 6, 82-94.

https://doi.org/10.4236/jfcmv.2018.62008

Received: November 13, 2017

Accepted: February 23, 2018

Published: April 18, 2018

Copyright ( 92018 by authors and Scientific Research Publishing Inc. This work is licensed under the Creative Commons Attribution International License (CC BY 4.0).

http://creativecommons.org/licenses/by/4.0/

\section{(c) (i) Open Access}

\begin{abstract}
Beyond conventional methods for $\mathrm{CO}_{2}$ capture and storage, a promising technology of sub-seabed $\mathrm{CO}_{2}$ storage in the form of gas hydrate has come into the limelight nowadays. In order to estimate $\mathrm{CO}_{2}$ storage capacity in the real sub-seabed sediments by gas hydrate, a large-scale geological model with the radius of $100 \mathrm{~m}$ and the thickness of $160 \mathrm{~m}$ was built in this study, and the processes of $\mathrm{CO}_{2}$ injection and $\mathrm{CO}_{2}$ hydrate formation in the sediments with two-phase flow were simulated numerically at three different injection rates of 10 ton/day, 50 ton/day, and 100 ton/day for an injection period of 150 days. Then, the evolutions of $\mathrm{CO}_{2}$ reaction, free $\mathrm{CO}_{2}$, and hydrate formation over time were analyzed quantitatively, and the spatial distributions of the physical properties in the sediments were presented to investigate the behaviors of $\mathrm{CO}_{2}$ hydrate formation in the sediments with two-phase flow. For $\mathrm{CO}_{2}$ storage capacity, a total amount of 15,000-ton $\mathrm{CO}_{2}$ can be stored safely in the sediments at the injection rate of 100 ton/day for 150 days, and a maximum amount of 36,500-ton $\mathrm{CO}_{2}$ could be stored in the sub-seabed sediments per year for a $\mathrm{CO}_{2}$ storage reservoir with the thickness of $100 \mathrm{~m}$. For the practical scenario, an average value of $1 \mathrm{ton} / \mathrm{day} / \mathrm{m}$ could be used to determine the actual injection rate based on the thickness of the real sub-seabed sediments.
\end{abstract}

\section{Keywords}

$\mathrm{CO}_{2}$ Capture and Storage, Sub-Seabed $\mathrm{CO}_{2}$ Storage, $\mathrm{CO}_{2}$ Hydrate Formation, Two-Phase Flow, Sub-Seabed Sediments, $\mathrm{CO}_{2}$ Storage Capacity

\section{Introduction}

Global warming has been identified as one of the most serious global environmental issues for the last several decades. According to the Climate Change 2014 ${ }^{*}$ A part of this paper was presented at 14th International Conference Fluid Dynamics (ICFD14) in Sendai, 1-3 Nov. 2017. 
by IPCC [1], the globally averaged combined land and ocean surface temperature anomaly has risen by around $0.85^{\circ} \mathrm{C}$ from 1880 to 2012 . Moreover, it is likely to rise by $2.6^{\circ} \mathrm{C}-4.8^{\circ} \mathrm{C}$ by the end of the 21 st century. As a result, the temperature rise causes the thaw of the mountain glaciers and snow cover globally, leading to the sea level change. Over the period from 1901 to 2010, the globally averaged sea level has risen by $0.19 \mathrm{~m}$, and will further rise by around $0.07-0.36 \mathrm{~m}$ by 2050 , and around $0.09-0.69 \mathrm{~m}$ by 2080 [2].

As the major cause for global warming, anthropogenic $\mathrm{CO}_{2}$ emission into the atmosphere has increased dramatically over the past few decades, and caused negative and irreversible effects on the environment and ecosystems [1]. In order to mitigate global warming, $\mathrm{CO}_{2}$ capture and storage (CCS) is widely regarded as one of the most effective countermeasures for $\mathrm{CO}_{2}$ emission reduction. The conventional methods for CCS usually refer to $\mathrm{CO}_{2}$ injection and storage into the deep saline aquifers onshore and shallow offshore [3] [4] [5] [6] [7], which have been considered as the main stream for CCS. However, there is a social concern about the stability and security of $\mathrm{CO}_{2}$ storage in the deep saline aquifers [8]. If the cap rocks above the reservoir crack due to the earthquake, the injected $\mathrm{CO}_{2}$ may not be able to keep stable in the deep saline aquifers, and seep out of the cap rocks through the cracks. In the worst-case scenario, the injected $\mathrm{CO}_{2}$ may leak into the ocean, and cause ocean acidification [9] [10] [11].

A novel approach of sub-seabed $\mathrm{CO}_{2}$ storage in the form of gas hydrate attracts much attention nowadays [12]. In this technology, the high-permeability sand layers surrounded by the low-permeability mud layers in the shallow sub-seabed sediments are selected as the target geological strata for $\mathrm{CO}_{2}$ storage, because the sand layers can serve as the reservoir, and the mud layers can serve as the overburden and underburden to restrain $\mathrm{CO}_{2}$ leakage. During the injection, $\mathrm{CO}_{2}$ flows into the pore space of the sand layers, and forms $\mathrm{CO}_{2}$ hydrate gradually with the underground water under low temperature and high pressure conditions. As a result, $\mathrm{CO}_{2}$ can be trapped stably inside the solid hydrate, and the risk of $\mathrm{CO}_{2}$ leakage can also be reduced greatly. However, there is also an obstacle for this new technology. After the injection, the permeability of the sand layers near the injection well will drop sharply due to the hydrate formation, which may cause the $\mathrm{CO}_{2}$ flow blockage, and hinder the further $\mathrm{CO}_{2}$ injection. Therefore, in order to store a large amount of $\mathrm{CO}_{2}$ in the sub-seabed sediments by gas hydrate, it is important and essential to choose a proper $\mathrm{CO}_{2}$ injection rate, and ensure $\mathrm{CO}_{2}$ to spread over a wide area after the injection.

Although the previous researchers have conducted a lot of studies on the topic of sub-seabed $\mathrm{CO}_{2}$ storage by gas hydrate, they mainly focused on the lab-scale experiments and simulations [13]-[18]. The behaviors of $\mathrm{CO}_{2}$ hydrate formation in the real sub-seabed sediments with two-phase flow still remain unknown, because few investigations have been dedicated to the large-scale simulations for a relatively long injection period measured by month.

For the practical application of this new technology, a numerical simulator incorporated with an integrated model for $\mathrm{CO}_{2}$ hydrate formation in the sand 
sediments was developed in our previous study [19]. Then, this simulator was employed to the experimental cases for the determination of the unknown model parameters. In this study, this simulator is applied to the numerical simulations of $\mathrm{CO}_{2}$ injection and $\mathrm{CO}_{2}$ hydrate formation in a large-scale geological model for an injection period as long as 150 days (nearly five months), to estimate $\mathrm{CO}_{2}$ storage capacity in the real sub-seabed sediments by gas hydrate.

\section{Numerical Modeling}

\subsection{Governing Equations}

The numerical simulator used in this study was developed by modifying a gas-liquid two-phase flow code, TOUGH + HYDRATE v1.0 [20]. This improved simulator can describe the mass balance for water, gas, hydrate, heat, and $\mathrm{CO}_{2}$ mass fraction in the aqueous phase using the finite difference method. In this simulator, a series of five primary variables $\left(P, T, S_{A}, S_{G}\right.$ and $\left.X_{A}^{\mathrm{CO}_{2}}\right)$ are solved iteratively by Newton-Raphson Method using five governing equations (mass balance equations for aqueous, gas, and hydrate phases, heat balance equation, and $\mathrm{CO}_{2}$ mass balance equation in the aqueous phase) as below, respectively [14]:

$$
\begin{gathered}
\partial\left(\phi\left(S_{G} \rho_{G} X_{G}^{\mathrm{H}_{2} \mathrm{O}}+S_{A} \rho_{A} X_{A}^{\mathrm{H}_{2} \mathrm{O}}\right)\right) / \partial t=\boldsymbol{F}_{G} X_{G}^{\mathrm{H}_{2} \mathrm{O}}+\boldsymbol{F}_{A} X_{A}^{\mathrm{H}_{2} \mathrm{O}}-Q_{H} X_{H}^{\mathrm{H}_{2} \mathrm{O}}, \\
\partial\left(\phi\left(S_{G} \rho_{G} X_{G}^{\mathrm{CO}_{2}}+S_{A} \rho_{A} X_{A}^{\mathrm{CO}_{2}}\right)\right) / \partial t \\
=\boldsymbol{F}_{G} X_{G}^{\mathrm{CO}_{2}}+\boldsymbol{F}_{A} X_{A}^{\mathrm{CO}_{2}}+\boldsymbol{J}_{G}+\boldsymbol{J}_{A}-Q_{H} X_{H}^{\mathrm{CO}_{2}}+Q_{i n j}^{\mathrm{CO}_{2}}, \\
\partial\left(\phi S_{H} \rho_{H}\right) / \partial t=Q_{H}^{h y d}, \\
\partial\left((1-\phi) \rho_{R} C_{R} T+\sum_{\beta \equiv A, G, H} \phi S_{\beta} \rho_{\beta} U_{\beta}\right) / \partial t \\
=-\lambda_{m} \nabla T+\sum_{\beta \equiv A, G} h_{\beta}\left(\mathbf{F}_{\beta}+\mathbf{J}_{\beta}\right)+\sum_{\beta \equiv A, G} h_{\beta} Q_{\beta}+Q_{H} \Delta H_{H}+Q_{s o l}^{\mathrm{CO}_{2}} \Delta H_{s o l}^{\mathrm{CO}_{2}} \\
\partial\left(\phi S_{A} \rho_{A} X_{A}^{\mathrm{CO}_{2}}\right) / \partial t=Q_{\text {sol }}^{\mathrm{CO}_{2}}+\mathbf{F}_{A} X_{A}^{\mathrm{CO}_{2}}+\mathbf{J}_{A}^{\mathrm{CO}_{2}}-Q_{H} X_{H}^{\mathrm{CO}_{2}},
\end{gathered}
$$

where $S_{\beta}$ is the volume fraction (i.e. saturation) of phase $\beta \equiv A, G, H\left(\mathrm{~m}^{3} / \mathrm{m}^{3}\right)$, $\rho_{\beta}$ is the density of phase $\beta \equiv A, G, H\left(\mathrm{~kg} / \mathrm{m}^{3}\right)$, and $X_{\beta}^{\kappa}$ is the mass fraction of the component $\kappa \equiv \mathrm{H}_{2} \mathrm{O}, \mathrm{CO}_{2}$, hydrate in phase $\beta \equiv A, G, H(\mathrm{~kg} / \mathrm{kg}) . \quad \boldsymbol{F}_{\beta}$ is the flux term of phase $\beta \equiv A, G\left(\mathrm{~kg} / \mathrm{m}^{3} / \mathrm{s}\right), \quad \boldsymbol{J}_{\beta}$ is the diffusion term of phase $\beta \equiv A$, $G\left(\mathrm{~kg} / \mathrm{m}^{3} / \mathrm{s}\right), Q_{\beta}$ is the source/sink term of phase $\beta \equiv A, G\left(\mathrm{~kg} / \mathrm{m}^{3} / \mathrm{s}\right), h_{\beta}$ is the specific enthalpy of phase $\beta \equiv A, G(\mathrm{~J} / \mathrm{kg})$, and $U_{\beta}$ is the specific internal energy of phase $\beta \equiv A, G, H(\mathrm{~J} / \mathrm{kg}) . P$ is the pressure $(\mathrm{Pa}), T$ is the absolute temperature $(\mathrm{K})$, and $\lambda_{m}$ is the composite thermal conductivity $(\mathrm{W} / \mathrm{m} / \mathrm{K}) . \phi$ is the porosity of the porous medium $(-), \rho_{R}$ is the density of the porous medium $\left(\mathrm{kg} / \mathrm{m}^{3}\right)$, and $C_{R}$ is the specific heat capacity of the porous medium $(\mathrm{J} / \mathrm{kg} / \mathrm{K})$. $Q_{H}$ is the total hydrate formation rate $\left(\mathrm{kg} / \mathrm{m}^{3} / \mathrm{s}\right)$, and $\Delta H_{H}$ is the enthalpy change during hydrate formation/dissociation $(\mathrm{J} / \mathrm{kg}) . Q_{\mathrm{sol}}^{\mathrm{CO}_{2}}$ is $\mathrm{CO}_{2}$ dissolution rate in the aqueous phase $\left(\mathrm{kg} / \mathrm{m}^{3} / \mathrm{s}\right), \Delta H_{\text {sol }}^{\mathrm{CO}_{2}}$ is the enthalpy change during $\mathrm{CO}_{2}$ 
dissolution (J/kg), and $Q_{i n j}^{\mathrm{CO}_{2}}$ is $\mathrm{CO}_{2}$ injection rate $\left(\mathrm{kg} / \mathrm{m}^{3} / \mathrm{s}\right)$.

\section{2. $\mathrm{CO}_{2}$ Hydrate Formation Model}

As mentioned before, in our previous study [19], an integrated model for $\mathrm{CO}_{2}$ hydrate formation in the sand sediments was proposed to predict hydrate formation morphologies based on the formation locations in the sand sediments. In this model, $\mathrm{CO}_{2}$ hydrate is assumed to form at three different locations in the sand sediments, and the total hydrate formation rate $Q_{H}$ is described as below:

$$
Q_{H}=\delta Q_{H 1}+Q_{H 2}+Q_{H 3},
$$

where $\delta$ is a switch to determine whether the gas front exists in a computational cell $(\delta=1)$ or not $(\delta=0) . Q_{H 1}, Q_{H 2}$, and $Q_{H 3}$ are the corresponding hydrate formation rates on the gas front, on the hydrate film, and on the surface of the sand particles behind the gas front $\left(\mathrm{kg} / \mathrm{m}^{3} / \mathrm{s}\right)$, respectively, which are given as below:

$$
\begin{gathered}
Q_{H 1}=M_{H} k_{f} x_{1} A_{1}\left(f_{G}^{\mathrm{CO}_{2}}-f_{e q}^{\mathrm{CO}_{2}}\right)+M_{H} k_{f}\left(1-x_{1}\right) A_{1}\left(f_{I 1}^{\mathrm{CO}_{2}}-f_{e q}^{\mathrm{CO}_{2}}\right)-Q_{H 1 \rightarrow 3}, \\
Q_{H 2}=M_{H} k_{f} x_{2} A_{2}\left(f_{G}^{\mathrm{CO}_{2}}-f_{e q}^{\mathrm{CO}_{2}}\right)+M_{H} k_{f}\left(1-x_{2}\right) A_{2}\left(f_{I 2}^{\mathrm{CO}_{2}}-f_{e q}^{\mathrm{CO}_{2}}\right), \\
Q_{H 3}=M_{H} k_{f} A_{S}\left(f_{A}^{\mathrm{CO}_{2}}-f_{e q}^{\mathrm{CO}_{2}}\right)+\delta Q_{H 1 \rightarrow 3},
\end{gathered}
$$

where $M_{H}$ is the molar mass of $\mathrm{CO}_{2}$ hydrate $(\mathrm{kg} / \mathrm{mol})$, and $k_{f}$ is the intrinsic rate constant of $\mathrm{CO}_{2}$ hydrate formation $\left(\mathrm{mol} / \mathrm{m}^{2} / \mathrm{Pa} / \mathrm{s}\right) . \quad x_{1}$ and $x_{2}$ are the rupture ratios on the gas front and behind the gas front (-), respectively. $A_{1}$, $A_{2}$, and $A_{S}$ are the gas-liquid interfacial area on the gas front and behind the gas front, and the sand surface area $\left(\mathrm{m}^{2} / \mathrm{m}^{3}\right)$, respectively. $f_{G}^{\mathrm{CO}_{2}}, f_{A}^{\mathrm{CO}_{2}}, f_{e q}^{\mathrm{CO}_{2}}$, $f_{I 1}^{\mathrm{CO}_{2}}$, and $f_{I 2}^{\mathrm{CO}_{2}}$ are $\mathrm{CO}_{2}$ fugacity in the gas phase, in the aqueous phase, at the three-phase equilibrium point, at the gas-liquid interface on the gas front and behind the gas front $(\mathrm{Pa})$, respectively. $Q_{H 1 \rightarrow 3}$ is the hydrate formation rate transferred from $Q_{H 1}$ to $Q_{H 3}\left(\mathrm{~kg} / \mathrm{m}^{3} / \mathrm{s}\right)$. For each sub-model in this integrated model, one can find all the details in our previous study [19].

\section{Model Construction}

\subsection{Geological Model}

For the large-scale geological model simulating the real sub-seabed sediments, an axisymmetric cylinder with a radius of $100 \mathrm{~m}$ and a thickness of $160 \mathrm{~m}$ is built in this study, as shown in Figure 1. This sediment model is assumed to be located at the depth of $870-1030 \mathrm{~m}$ from the sea surface (at the water depth of 500 $\mathrm{m}$ ), and divided into three domains from top to bottom: 1) overburden, 2) $\mathrm{CO}_{2}$ storage reservoir, and 3) underburden. The $\mathrm{CO}_{2}$ storage reservoir is set to be composed of sand layers with the thickness of $100 \mathrm{~m}$, referring to the shallow reservoir (approximately $100 \mathrm{~m}$ thick) used for Tomakomai CCS Demonstration Project of Japan [21]. The overburden and underburden are both set to be composed of mud layers with the thickness of $30 \mathrm{~m}$. According to the previous report 


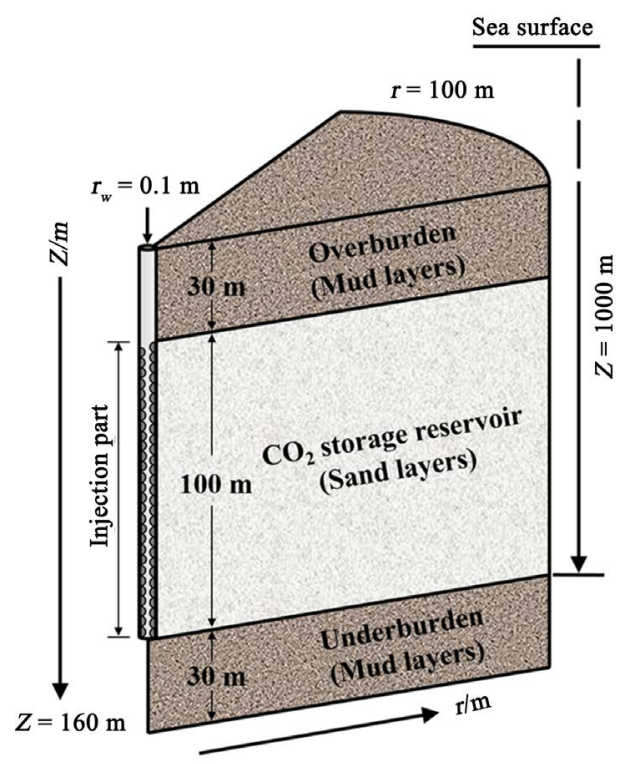

Figure 1. Schematic diagram of the sub-seabed sediment model built in this study.

by Sun et al. [22], it may be sufficient for these 30-m-thick overburden and underburden layers to simulate the boundary effects of heat exchange and pressure propagation.

In addition, an injection well is located at the center of the sediment model, which is used for $\mathrm{CO}_{2}$ injection. In order to determine the length of the injection part, the $\mathrm{CO}_{2}$ flow direction in the reservoir has been considered as a main factor in this study. After the injection, $\mathrm{CO}_{2}$ will not only flow horizontally in the reservoir, but also flow upward due to the buoyancy. If the length of the injection part is set to be smaller than the thickness of the $\mathrm{CO}_{2}$ storage reservoir, the injected $\mathrm{CO}_{2}$ may only distribute and form hydrate at the upper part of the reservoir, or in the vicinity of the injection well, which will increase the risk of the $\mathrm{CO}_{2}$ flow blockage. Based on this reason, the injection part is also set to be 100 $\mathrm{m}$, which equals to the thickness of the $\mathrm{CO}_{2}$ storage reservoir, to ensure that $\mathrm{CO}_{2}$ can spread over a wide area after the injection, and flow smoothly in the reservoir without the $\mathrm{CO}_{2}$ flow blockage.

\subsection{Computational Conditions}

The pore water pressure of the sediment model is assumed to be hydrostatic, and the initial hydrostatic pore water pressure $P_{p w}(\mathrm{MPa})$ can be calculated according to the empirical equation as below [23]:

$$
P_{p w}=P_{a t m}+\rho_{s w} g(h+z) \times 10^{-6},
$$

where $P_{a t m}$ is the standard atmospheric pressure (MPa), $\rho_{s w}$ is the sea water density $\left(\mathrm{kg} / \mathrm{m}^{3}\right), g$ is the gravitational acceleration $\left(\mathrm{m} / \mathrm{s}^{2}\right), h$ and $z$ are the water depth, and the depth of the sediments from the seafloor $(\mathrm{m})$, respectively.

For the initial temperature condition in the sediment model, the geothermal 
gradient is taken into account. Other main physical properties of the sediment model refer to the field parameters used for the numerical simulations of gas production behavior from methane hydrate reservoir at the first offshore test site in the eastern Nankai Trough, Japan (2013) [22]. The model parameters used in this study are listed in Table 1 . It is worth mentioning that by the preliminary calculations, it is confirmed that the initial pressure and temperature conditions in the $\mathrm{CO}_{2}$ storage reservoir are located within the hydrate stability zone according to the phase diagram of $\mathrm{CO}_{2}$ hydrate proposed by Kamath [24]. This indicates that the initial pressure and temperature conditions determined in this study are appropriate and suitable for $\mathrm{CO}_{2}$ hydrate formation, and hydrate can form in the reservoir after the injection. Besides, the intrinsic permeability of the overburden and underburden is set to be 100 times smaller than that of the $\mathrm{CO}_{2}$ storage reservoir, so that the overburden and underburden can both serve as the low-permeability layers to restrain $\mathrm{CO}_{2}$ leakage.

\section{Simulation Results and Discussion}

In order to estimate $\mathrm{CO}_{2}$ storage capacity in the sediment model built in this study, a proper $\mathrm{CO}_{2}$ injection rate needs to be determined in advance. By the preliminary simulations, it is found that if the injection rate is set to be larger than 100 ton/day, the $\mathrm{CO}_{2}$ flow blockage will occur at the early stage of the injection process. Therefore, three moderate injection rates of 10 ton/day, 50 ton/day, and 100 ton/day are chosen for Case 1 - Case 3. These three cases are also used for the sensitivity analysis to investigate the influence of the injection rate on the behaviors of $\mathrm{CO}_{2}$ reaction and hydrate formation. Besides, the injection period is set to be 150 days (nearly five months), so the total amounts of $\mathrm{CO}_{2}$ injection are 1500 ton, 7500 ton, and 15,000 ton, respectively.

Table 1 . The physical properties of the sediment model.

\begin{tabular}{cc} 
Parameter & Value \& Unit \\
\hline Pnitial pressure condition in $\mathrm{CO}_{2}$ storage reservoir & $9.12-10.12 \mathrm{MPa}$ \\
Initial temperature condition in $\mathrm{CO}_{2}$ storage reservoir & $12.0^{\circ} \mathrm{C}-15.0^{\circ} \mathrm{C}$ \\
Pntrinsic permeability of $\mathrm{CO}_{2}$ storage reservoir & 0.41 \\
Initial water saturation & $1.0 \times 10^{-12} \mathrm{~m}^{2}(=1000 \mathrm{mD})$ \\
Geothermal gradient & $1.0 \times 10^{-14} \mathrm{~m}^{2}(=10 \mathrm{mD})$ \\
Sea water density & $1.00 \mathrm{~m} / \mathrm{m}^{3}$ \\
Grain density & $30.0^{\circ} \mathrm{C} / \mathrm{km}$ \\
Grain specific heat & $1022 \mathrm{~kg} / \mathrm{m}^{3}$ \\
Dry thermal conductivity & $2650 \mathrm{~kg} / \mathrm{m}^{3}$ \\
Wet thermal conductivity of overburden and underburden & $792 \mathrm{~J} / \mathrm{kg} /{ }^{\circ} \mathrm{C}$
\end{tabular}




\subsection{Evolutions of $\mathrm{CO}_{2}$ Reaction, Free $\mathrm{CO}_{2}$, and Hydrate Formation in the Sediment Model}

Figure 2 shows the evolutions of $\mathrm{CO}_{2}$ reaction, free $\mathrm{CO}_{2}$, and hydrate formation in the sediment model during the whole injection period for Case 1 - Case 3. As can be observed in Figure 2(a), the mass rates of $\mathrm{CO}_{2}$ reaction reach the peaks at the beginning of the injection process for all the three cases. The reason is that, as mentioned before, the initial pressure and temperature conditions in the $\mathrm{CO}_{2}$ storage reservoir are suitable for $\mathrm{CO}_{2}$ hydrate formation, and as soon as $\mathrm{CO}_{2}$ is injected into the reservoir, it forms hydrate immediately, leading to the jump in the mass rate of $\mathrm{CO}_{2}$ reaction. On the other hand, during the processes of $\mathrm{CO}_{2}$ dissociation into the aqueous phase and $\mathrm{CO}_{2}$ hydrate formation, a large amount of heat is released in a short time, resulting in the abrupt temperature rise in the sediments, which will have a negative effect on the further hydrate formation. Therefore, the mass rate of $\mathrm{CO}_{2}$ reaction drops sharply after the peaks, and the heat release decreases accordingly. This phenomenon repeats again and again, and it is the reason that there are many fluctuations on the curves of the mass rates of $\mathrm{CO}_{2}$ reaction for all the three cases, especially in Case 3. In addition, it can also be seen that the larger the injection rate is, the more intense the fluctuations become, because the amount of heat release also becomes larger. During the whole injection period, the average mass rates of $\mathrm{CO}_{2}$ reaction in the reservoir are approximately 0.20 ton/day, 0.90 ton/day, and 1.86 ton/day, respectively, for Case 1 - Case 3.

By the integral of the mass rate of $\mathrm{CO}_{2}$ reaction, the amount of $\mathrm{CO}_{2}$ reaction over time can be obtained accordingly, as shown in Figure 2(b). Since the curves of the mass rates of $\mathrm{CO}_{2}$ reaction are fluctuant in Figure 2(a), the curves of the amount of $\mathrm{CO}_{2}$ reaction are also fluctuant, especially in Case 3, and present linear behaviors by appearance for 150 days. If given a much longer injection period, the status in the sediments will get close to the $\mathrm{CO}_{2}$ flow blockage gradually. As a result, the amount of $\mathrm{CO}_{2}$ reaction may approach to a maximum value, and the curves may present exponential behaviors by appearance. By the end of the whole injection period of 150 days, the total amounts of $\mathrm{CO}_{2}$ reaction in the reservoir reach approximately 32.9 ton, 138.0 ton, and 286.5 ton, respectively, for Case 1 - Case 3.

After the injection, a part of $\mathrm{CO}_{2}$ neither forms hydrate nor dissolves into the aqueous phase. Instead, it just remains in the reservoir as free $\mathrm{CO}_{2}$. Figure 2(c) shows the amount of free $\mathrm{CO}_{2}$ in the reservoir over time. As can be seen in the figure, there are also some fluctuations on the curves for all the three cases. However, the fluctuations in Figure 2(c) are just opposite to those in Figure 2(b), because the more $\mathrm{CO}_{2}$ participates in the reaction and forms hydrate, the less it will remain in the reservoir as free $\mathrm{CO}_{2}$. With the increase of the injection rate, the amount of free $\mathrm{CO}_{2}$ also rises accordingly. By the end of the whole injection period, the total amount of free $\mathrm{CO}_{2}$ in the reservoir reach approximately 104.2 ton, 646.3 ton, and 1310.2 ton, respectively, for Case 1 - Case 3. 


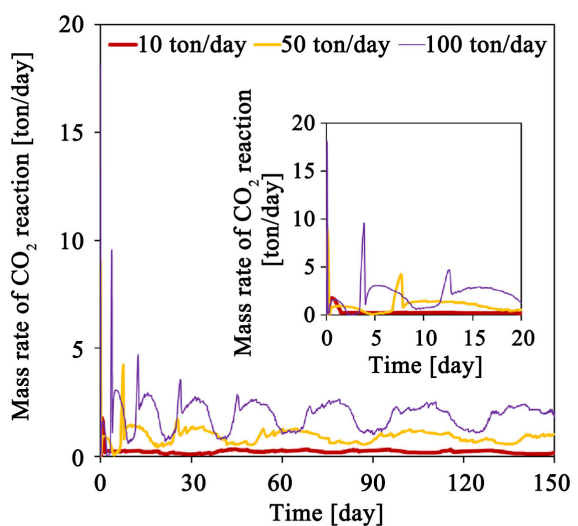

(a)

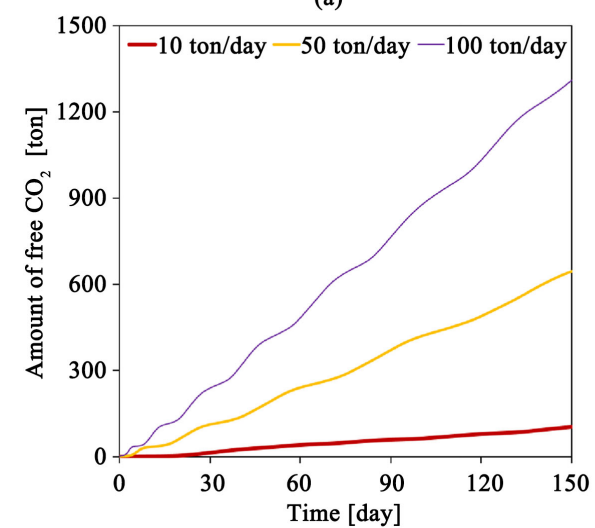

(c)

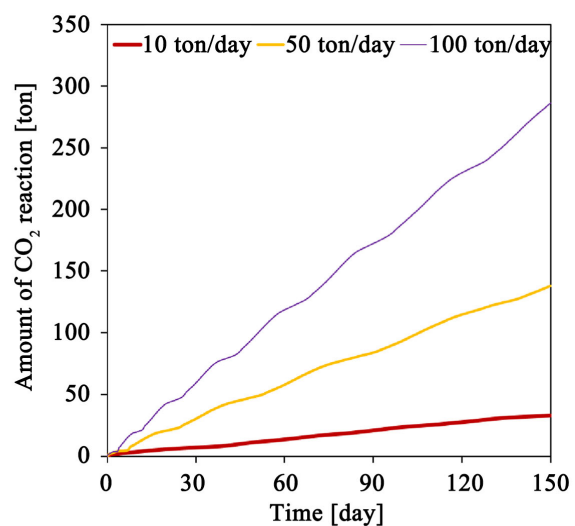

(b)

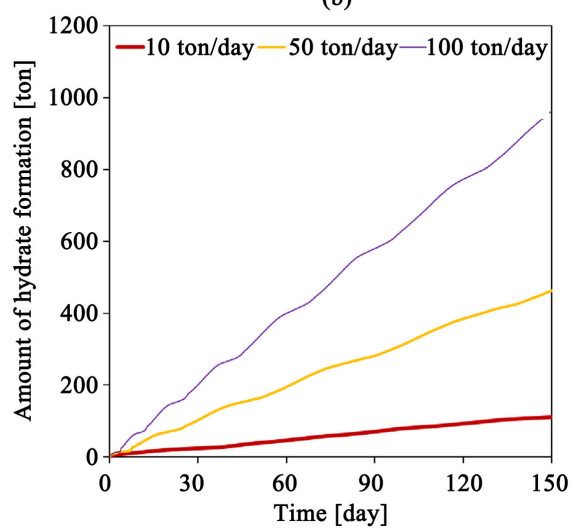

(d)

Figure 2. Evolutions of $\mathrm{CO}_{2}$ reaction, free $\mathrm{CO}_{2}$, and hydrate formation in the sediment model during 150 days for Case 1 - Case 3. (a) The mass rate of $\mathrm{CO}_{2}$ reaction [ton/day]; (b) The amount of $\mathrm{CO}_{2}$ reaction [ton]; (c) The amount of free $\mathrm{CO}_{2}$ [ton]; (d) The amount of $\mathrm{CO}_{2}$ hydrate formation [ton].

For the amount of $\mathrm{CO}_{2}$ hydrate formation in the reservoir, the curves in Figure 2(d) are actually in the same shapes as those in Figure 2(b), because the amount of $\mathrm{CO}_{2}$ reaction means the part of $\mathrm{CO}_{2}$ which forms hydrate, and it is closely related to the amount of $\mathrm{CO}_{2}$ hydrate formation. Besides, it is clearly observed that the more $\mathrm{CO}_{2}$ is injected into the reservoir, the more $\mathrm{CO}_{2}$ hydrate forms. By the end of the whole injection period, the total amount of $\mathrm{CO}_{2}$ hydrate formation in the reservoir reach approximately 110.5 ton, 462.7 ton, and 960.7 ton, respectively, for Case 1 - Case 3.

\subsection{Spatial Distributions of Physical Properties in the Sediment Model}

Since the total amounts of $\mathrm{CO}_{2}$ reaction and $\mathrm{CO}_{2}$ hydrate formation are the largest in Case 3, this case has been extracted as a best case to investigate the behaviors of $\mathrm{CO}_{2}$ hydrate formation in the sediments with two-phase flow. Figure 3 shows the spatial distributions of the physical properties in the sediment model after 30 days, 90 days, and 150 days, respectively, for Case 3.

As can be seen in Figure 3(a), after the injection, the isopiestic lines in the sediment model have been disturbed, and showed an upward shift in the vicinity 


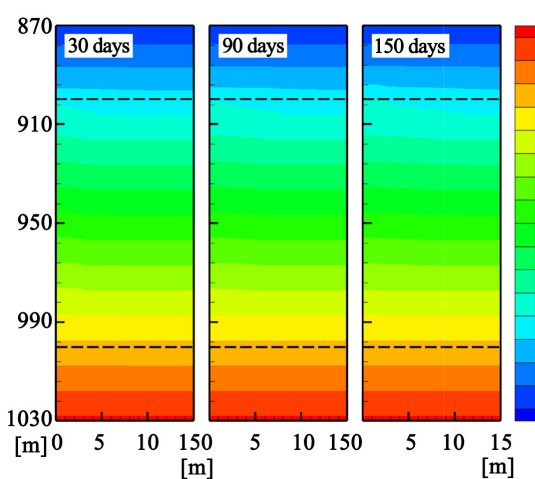

(a)

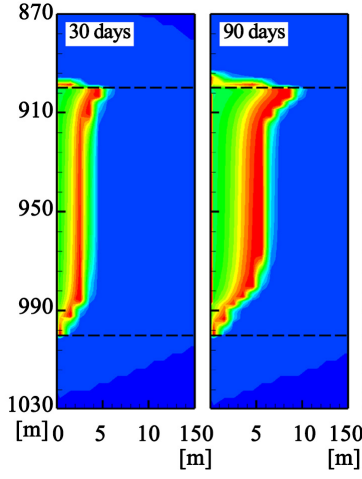

(c)

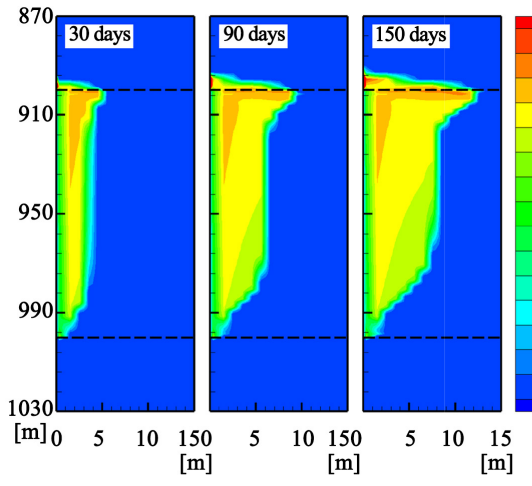

(e)

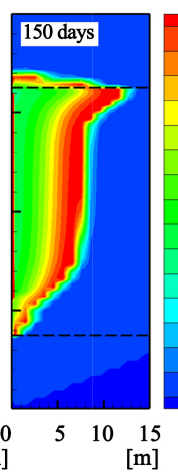

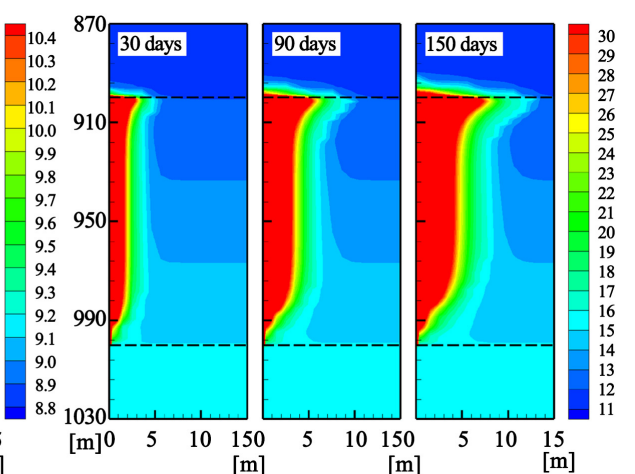

(b)
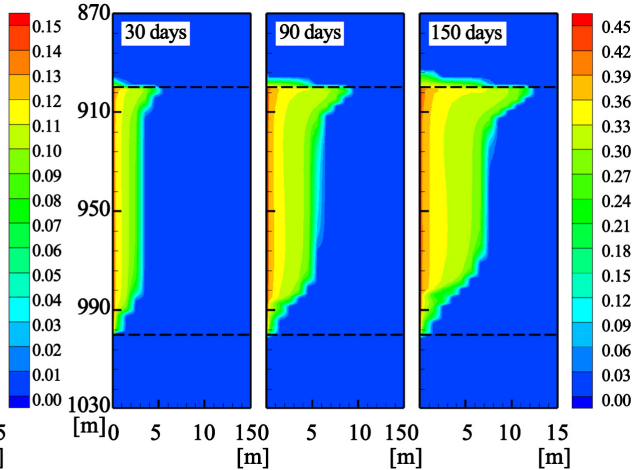

(d)
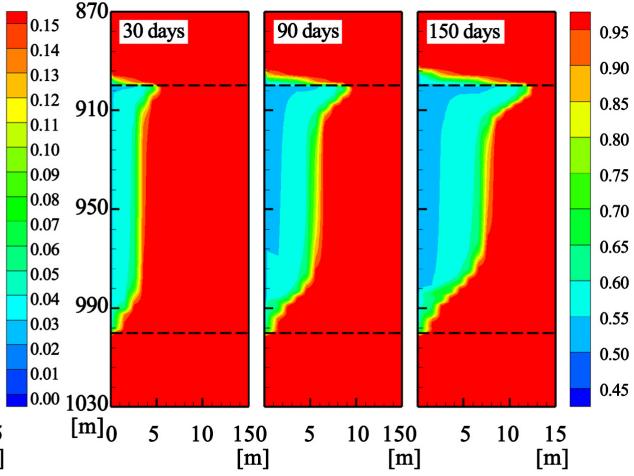

Figure 3. Spatial distributions of the physical properties in the sediment model during 150 days for Case 3. (a) Pressure [MPa]; (b) Temperature [ $\left.{ }^{\circ} \mathrm{C}\right]$; (c) $\mathrm{CO}_{2}$ mass fraction in the aqueous phase $[\mathrm{kg} / \mathrm{kg}]$; (d) $\mathrm{CO}_{2}$ saturation $\left[\mathrm{m}^{3} / \mathrm{m}^{3}\right]$; (e) Hydrate saturation $\left[\mathrm{m}^{3} / \mathrm{m}^{3}\right]$; (f) Water saturation $\left[\mathrm{m}^{3} / \mathrm{m}^{3}\right]$.

of the injection well, especially at the depth of $895-910 \mathrm{~m}$. This is because that after $\mathrm{CO}_{2}$ hydrate forms in the reservoir, the solid hydrate occupies the pore space of the sediments, and causes the reduction in the effective permeability, which will hinder the $\mathrm{CO}_{2}$ flow to a certain extent. As a result, the injected $\mathrm{CO}_{2}$ accumulates in the vicinity of the injection well, leading to the upward shift of the isopiestic lines as mentioned before. On the other hand, during the injection, the temperature jumps significantly in the reservoir, and a high temperature zone forms in the sediments, as shown in Figure 3(b). For the heat source of the high temperature zone, some of the heat comes from $\mathrm{CO}_{2}$ hydrate formation 
heat, but most of the heat actually comes from $\mathrm{CO}_{2}$ dissociation heat into the aqueous phase. This can be directly proved by Figure 3(c), in which it is clearly observed that during the process of the two-phase flow, a narrow zone of high $\mathrm{CO}_{2}$ mass fraction due to $\mathrm{CO}_{2}$ dissociation into the aqueous phase appears in the reservoir. This narrow zone moves forward with the $\mathrm{CO}_{2}$ flow, and expands gradually in the radial direction, which indicates that the amount of $\mathrm{CO}_{2}$ dissociation becomes larger during the process of the two-phase flow, and releases a great deal of heat in the reservoir. Meanwhile, due to the low thermal conductivities of the sand layers and mud layers, the heat generated by $\mathrm{CO}_{2}$ hydrate formation and $\mathrm{CO}_{2}$ dissociation increases and accumulates in the reservoir instead of being discharged from the sediments, resulting in the high temperature zone as shown in Figure 3(b).

In order to obtain a better understanding of the behaviors of $\mathrm{CO}_{2}$ hydrate formation in the sediments with two-phase flow, the evolutions of $\mathrm{CO}_{2}$ saturation, hydrate saturation, and water saturation over time are presented in Figures 3(d)-(f), respectively. As can been seen in Figure 3(d), after the injection, $\mathrm{CO}_{2}$ nearly moves horizontally in the reservoir, leading to the graded distribution of the $\mathrm{CO}_{2}$ saturation in the radial direction. However, since the density of $\mathrm{CO}_{2}$ is smaller than that of water, the injected $\mathrm{CO}_{2}$ also flows upward gradually. Although the intrinsic permeability of the overburden and underburden is set to be 100 times smaller than that of the $\mathrm{CO}_{2}$ storage reservoir, a small part of $\mathrm{CO}_{2}$ still seeps out of the reservoir, and leaks into the overburden due to the buoyancy. On the other hand, as shown in Figure 3(e), $\mathrm{CO}_{2}$ hydrate forms gradually in the reservoir as a result of the suitable temperature and pressure conditions, and generates a lot of heat as mentioned before. This part of $\mathrm{CO}_{2}$ hydrate formation heat, especially along with the large amount of $\mathrm{CO}_{2}$ dissociation heat, has a negative effect on the further hydrate formation, so the hydrate saturation in the reservoir shows a trend of heterogeneous distribution. Meanwhile, since the temperature and pressure conditions in the overburden are also within the hydrate stability zone, most of the leaked $\mathrm{CO}_{2}$ forms a thin layer of hydrate in the overburden, especially just above the injection well, where a high hydrate saturation spot can be observed clearly. This thin layer of hydrate may serve as a self-sealing cap, and restrain the further $\mathrm{CO}_{2}$ leakage, so that the injected $\mathrm{CO}_{2}$ can be stored safely in the sub-seabed sediments without leaking into the ocean. Besides, after the injection, $\mathrm{CO}_{2}$ pushes the aqueous phase forward in the radial direction, and a part of pore water is consumed to form hydrate, so the water saturation also displays a graded distribution, creating a low water saturation zone in the vicinity of the injection well, as shown in Figure 3(f).

\section{Conclusions}

For the estimation of $\mathrm{CO}_{2}$ storage capacity in the real sub-seabed sediments by gas hydrate, a large-scale geological model simulating the real sub-seabed sediments in the ocean was built in this study, and numerical simulations of $\mathrm{CO}_{2}$ in- 
jection and $\mathrm{CO}_{2}$ hydrate formation in the sediments with two-phase flow were conducted at three different injection rates of 10 ton/day, 50 ton/day, and 100 ton/day, respectively. It is found that, at the injection rate of 100 ton/day, a total amount of 15,000-ton $\mathrm{CO}_{2}$ can be injected into the sediments for an injection period of 150 days. After the injection, a part of $\mathrm{CO}_{2}$ can be stored in the sediments in the form of gas hydrate, and the rest part remains in the reservoir as free $\mathrm{CO}_{2}$ or dissolves into the aqueous phase. For a $\mathrm{CO}_{2}$ storage reservoir with the thickness of $100 \mathrm{~m}$ as built in this study, at the injection rate of 100 ton/day, i.e., averagely 1 ton/day/m, a maximum amount of 36,500-ton $\mathrm{CO}_{2}$ could be injected and stored in the sub-seabed sediments per year. For the practical scenario, this average value of $1 \mathrm{ton} / \mathrm{day} / \mathrm{m}$ could also be used to determine the actual injection rate based on the thickness of the real sub-seabed sediments.

Moreover, in order to investigate the behaviors of $\mathrm{CO}_{2}$ hydrate formation in the sediments with two-phase flow, the spatial distributions of the physical properties in the sediments over time were presented for the case of the injection rate of 100 ton/day. The simulation results indicate that during the injection process, a large amount of heat is released due to $\mathrm{CO}_{2}$ hydrate formation heat and $\mathrm{CO}_{2}$ dissociation heat into the aqueous phase, leading to a high temperature zone in the reservoir which has a negative effect on the hydrate formation. After the injection, $\mathrm{CO}_{2}$ not only flows horizontally in the reservoir, but also flows upward due to the buoyancy. As a result, a small part of $\mathrm{CO}_{2}$ permeates into the overburden, forms hydrate, and serves as a self-sealing cap to restrain the further $\mathrm{CO}_{2}$ leakage. Although the long-term injection and monitoring are still needed to fully evaluate the potential and feasibility of the technology of sub-seabed $\mathrm{CO}_{2}$ storage in the form of gas hydrate, it is reasonable to believe that this novel technology can be expected to be applied in the field demonstration in the future.

\section{Acknowledgements}

This work was supported by the Hirosaki University Grant for Exploratory Research by Young Scientists and Newly-appointed Scientists, and the Open Fund of Key Laboratory of Ocean Energy Utilization and Energy Conservation of Ministry of Education at Dalian University of Technology.

\section{References}

[1] (Core Writing Team) Pachauri, R.K. and Meyer, L.A. (2014) Climate Change 2014: Synthesis Report. Contribution of Working Groups I, II and III to the Fifth Assessment Report of the Intergovernmental Panel on Climate Change. IPCC, Geneva. http://www.ipcc.ch/report/ar5/syr/

[2] Hulme, M., Jenkins, G.J., Lu, X., Turnpenny, J.R., Mitchell, T.D., Jones, R.G., Lowe, J., Murphy, J.M., Hassell, D., Boorman, P., McDonald, R. and Hill, S. (2002) Climate Change Scenarios for the United Kingdom: The UKCIP02 Scientific Report, Tyndall Centre for Climate Change Research, School of Environmental Sciences, University of East Anglia, Norwich.

http://artefacts.ceda.ac.uk/badc_datadocs/link/UKCIP02_tech.pdf 
[3] Nordbotten, J.M., Celia, M.A. and Bachu, S. (2005) Injection and Storage of $\mathrm{CO}_{2}$ in Deep Saline Aquifers: Analytical Solution for $\mathrm{CO}_{2}$ Plume Evolution during Injection. Transport in Porous Media, 58, 339-360.

https://doi.org/10.1007/s11242-004-0670-9

[4] Goodman, A., Bromhal, G., Strazisar, B., Rodosta, T., Guthrie, W., Allen, D. and Guthrie, G. (2013) Comparison of Methods for Geologic Storage of Carbon Dioxide in Saline Formations. International Journal of Greenhouse Gas Control, 18, 329-342. https://doi.org/10.1016/j.ijggc.2013.07.016

[5] Bachu, S. (2015) Review of $\mathrm{CO}_{2}$ Storage Efficiency in Deep Saline Aquifers. International Journal of Greenhouse Gas Control, 40, 188-202.

https://doi.org/10.1016/j.ijggc.2015.01.007

[6] Birkholzer, J.T., Oldenburg, C. and Zhou, Q. (2015) $\mathrm{CO}_{2}$ Migration and Pressure Evolution in Deep Saline Aquifers. International Journal of Greenhouse Gas Control, 40, 203-220. https://doi.org/10.1016/j.ijggc.2015.03.022

[7] Gorecki, C.D., Ayash, S.C., Liu, G., Braunberger, J.R. and Dotzenrod, N.W. (2015) A Comparison of Volumetric and Dynamic $\mathrm{CO}_{2}$ Storage Efficiency in Deep Saline Formations. International Journal of Greenhouse Gas Control, 42, 213-225. https://doi.org/10.1016/j.ijggc.2015.07.018

[8] De Silva, G.P.D., Ranjith, P.G. and Perera, M.S.A. (2015) Geochemical Aspects of $\mathrm{CO}_{2}$ Sequestration in Deep Saline Aquifers: A Review. Fuel, 155, 128-143. https://doi.org/10.1016/j.fuel.2015.03.045

[9] Drange, H., Alendal, G. and Johannessen, O.M. (2001) Ocean Release of Fossil Fuel $\mathrm{CO}_{2}$ : A Case Study. Geophysical Research Letters, 28, 2637-2640. https://doi.org/10.1029/2000GL012609

[10] Kano, Y., Sato, T., Kita, J., Hirabayashi, S. and Tabeta, S. (2010) Multi-Scale Modelling of $\mathrm{CO}_{2}$ Dispersion Leaked from Seafloor off Japanese Coast. Marine Pollution Bulletin, 60, 215-224. https://doi.org/10.1016/j.marpolbul.2009.09.024

[11] Mori, C., Sato, T., Kano, Y., Oyama, H., Aleynik, D., Tsumune, D. and Maeda, Y. (2015) Numerical Study of the Fate of $\mathrm{CO}_{2}$ Purposefully Injected into the Sediment and Seeping from Seafloor in Ardmucknish Bay. International Journal of Greenhouse Gas Control, 38, 153-161. https://doi.org/10.1016/j.ijggc.2014.11.023

[12] Inui, M. and Sato, T. (2006) Economical Feasibility Study on $\mathrm{CO}_{2}$ Sequestration in the Form of Gas Hydrate under Seafloor. Journal of the Japan Society of Naval Architects and Ocean Engineers, 3, 35-46. (In Japanese)

[13] Kvamme, B., Graue, A., Buanes, T., Kuznetsova, T. and Ersland, G. (2007) Storage of $\mathrm{CO}_{2}$ in Natural Gas Hydrate Reservoirs and the Effect of Hydrate as an Extra Sealing in Cold Aquifers. International Journal of Greenhouse Gas Control, 1, 236-246. https://doi.org/10.1016/S1750-5836(06)00002-8

[14] Nakashima, T., Sato, T. and Inui, M. (2013) Numerical Modeling of Hydrate Formation in Sand Sediment Simulating Sub-Seabed $\mathrm{CO}_{2}$ Storage in the Form of Gas Hydrate. Energy Procedia, 37, 5986-5993. https://doi.org/10.1016/j.egypro.2013.06.526

[15] Seo, Y., Park, S., Kang, H., Ahn, Y., Lim, D., Kim, S., Lee, J., Lee, J., Ahn, T., Seo, Y. and Lee, H. (2016) Isostructural and Cage-Specific Replacement Occurring in sII Hydrate with External $\mathrm{CO}_{2} / \mathrm{N}_{2}$ Gas and Its Implications for Natural Gas Production and $\mathrm{CO}_{2}$ Storage. Applied Energy, 178, 579-586. https://doi.org/10.1016/j.apenergy.2016.06.072

[16] Jager, A., Vins, V., Span, R. and Hruby, J. (2016) Model for Gas Hydrates Applied to CCS Systems Part III. Results and Implementation in TREND 2.0. Fluid Phase 
Equilibria, 429, 55-66. https://doi.org/10.1016/j.fluid.2016.08.027

[17] Liu, Y., Wang, P., Yang, M., Zhao, Y., Zhao, J. and Song, Y. (2018) $\mathrm{CO}_{2}$ Sequestration in Depleted Methane Hydrate Sandy Reservoirs. Journal of Natural Gas Science and Engineering, 49, 428-434. https://doi.org/10.1016/j.jngse.2017.10.023

[18] Massah, M., Sun, D., Sharifi, H. and Englezos, P. (2018) Demonstration of Gas-Hydrate Assisted Carbon Dioxide Storage through Horizontal Injection in Lab-Scale Reservoir. The Journal of Chemical Thermodynamics, 117, 106-112. https://doi.org/10.1016/j.jct.2017.09.019

[19] Yu, T., Sato, T., Nakashima, T., Inui, M. and Oyama, H. (2016) An Integrated Model for $\mathrm{CO}_{2}$ Hydrate Formation in Sand Sediments for Sub-Seabed $\mathrm{CO}_{2}$ Storage. International Journal of Greenhouse Gas Control, 52, 250-269. https://doi.org/10.1016/j.ijggc.2016.07.009

[20] Moridis, G.J., Kowalsky, M.B. and Pruess, K. (2008) TOUGH+HYDRATE v1.0 User's Manual: A Code for the Simulation of System Behavior in Hydrate-Bearing Geologic Media. LBNL-0149E.

http://citeseerx.ist.psu.edu/viewdoc/download?doi=10.1.1.463.3045\&rep=rep1\&type $=\mathrm{pdf}$

[21] Tanaka, Y., Sawada, Y., Tanase, D., Tanaka, J., Shiomi, S. and Kasukawa, T. (2017) Tomakomai CCS Demonstration Project of Japan, $\mathrm{CO}_{2}$ Injection in Process. Energy Procedia, 114, 5836-5846. https://doi.org/10.1016/j.egypro.2017.03.1721

[22] Sun, J., Ning, F., Zhang, L., Liu, T., Peng, L., Liu, Z., Li, C. and Jiang, G. (2016) Numerical Simulation on Gas Production from Hydrate Reservoir at the 1st Offshore Test Site in the Eastern Nankai Trough. Journal of Natural Gas Science and Engineering, 30, 64-76. https://doi.org/10.1016/j.jngse.2016.01.036

[23] Song, H., Jiang, W., Zhang, W. and Hao, T. (2002) Progress on Marine Geophysical Studies of Gas Hydrates. Progress in Geophysics, 17, 224-229. (In Chinese)

[24] Kamath, V.A. (1984) Study of Heat Transfer Characteristics during Dissociation of Gas Hydrates in Porous Media. Ph.D. Thesis, University of Pittsburgh, Pittsburgh. 